variation. This is also true for the nuclei of type $\left(\begin{array}{l}A+2 \\ Z+1\end{array}\right)$, but these are not plotted to avoid confusing the figure. A more systematic knowledge of crosssections for many different series of nuclei will be necessary before we can be certain that they all vary regularly, and therefore provide a basis for explaining the regularities of the isotopic abundances shown in Fig. 1. But in seeking such an explanation we can, at least, be encouraged by the apparent regularity of Fig. 2.

Finally, we wish to note that the quasi-periodic form of Fig. 1 (and perhaps Fig. 2) is most easily interpreted in terms of closed nuclear shells. We therefore expect the maxima and minima of these curves to correspond with the so-called 'magic numbers'. The minima at $Z=40,50$ and 60 presumably correspond to $N=50, Z=50$ and $N=82$. But the minima at about $Z=16$ or 18 and $Z=26$ do not correspond to any previously accepted 'magic numbers'. However, the present set of 'magic numbers' has been obtained by a detailed but rather piecemeal examination of nuclear properties ${ }^{4}$, and it may well be that the numbers so obtained are not a complete set. The systematic examination of any one nuclear property ${ }^{5}$, such as that shown in Fig. 1, or in Fig. 2 if indeed capture cross-sections are found to vary systematically, can be expected to give us much more information than we have at present concerning nuclear shell structuro.

'Seaborg, Table of Isotopes, Rev. Mod. Phys. (Oct. 1949).

"Gamow and Critchfeld, "Theory of Atomic Nuclei" (Oxford, 1947), gives references to the older literature, and since then there have been several papers published by Alpher and Gamow in the

"Values of capture cross-sections taken mainly from Seren et al., Phys. Rev., y2, 888 (1947), and some, for example, nickel-62 from the Isotopic Chart of Perlman, Seaborg and Segré o Oct. 1947

'Mayer, Phys. Rev., 74, 235 (1948).

${ }^{8}$ Gordy, Phys. Rev., 76, 139 (1949), has systematically examined the nuclear quadrupole moments.

\section{HISTORY IN IRISH PEAT BOGS}

$\mathrm{A}^{\mathrm{T}}$

a symposium on research into Quaternary history held in London in October 1946, Prof. $\mathbf{K}$. Jessen's wise counsel to those interested in the history of the floras of the British Isles was to collect further evidence rather than spend time in speculation. His own very considerable contribution to this problem, the pollen-survey of Irish peat bogs, has now been published*. This survey, begun in 1934 at the instigation of the Committee for Quatermary Research in Ireland, has been supported by both Irish and Danish funds, and the analytical work was carried out in the botanical laboratories of the University of Copenhagen.

Forty-nine separate bogs, scattered through the island, have been sampled, to provide a history of both the flora and the vegetation. In this, the feature of greatest importance is the correlation of the various horizons in the Irish bogs with those of other European countries, in particular of England and Scandinavia. Thus, for the first time, a unified treatment of the vegetational history of western Europe could be attempted. In this connexion, probably the most important single item is the demonstration of an Allerød layer throughout Ireland which, as Zone II,

* Studies in Late Quaternary Deposits and Flora-History of Ireland, by Knud Jessen (Proc. Roy. Irish Acad., 52, Ser. B, No. 6, pp. 85̄-290, 1949). 258 . provides a firm base line for the dating of Late-glacial deposits which have now been recognized from Ireland, in the west, to north Germany and the eastern Baltic countries.

In the first recognized period of the Late-glacial (Zone I), there is clear evidence that the whole of Ireland was treeless. A limited number of species typical of open tundra constituted the meagre flore which, however, showed alpine affinities. Ireland, therefore, represented the western extremity of a wide, almost treeless belt which extended from the Atlantic coast at least as far as Gotland and north Germany. The nearest possible refuge during this glaciation for the majority of woodland species must have been far to the south of the present Irish coast, either on the coast of Brittany or perhaps on some now submerged portion of the Continental Shelf which was exposed at this time (for even in Lateglacial time (Zone III) the sea-level was at least 120 metres lower than at present).

In the Allerød period itself (Zone II), scattered copses of birch (Betula pubescens) appear to have occurred, while in the north-west Empetrum heath predominated. With the deterioration of the climate which produced Zone III, the birch copses may have survived only in sheltered localities, and a tundravegetation returned until the Post-glacial period was ushered in with more sustained amelioration.

Many of the best-known members of the American and Lusitanian elements in the Irish flora are not, however, woodland species. The finding of Eriocaulon pollen in Zone VIIa (Atlantic), although searched for unsuccessfully in earlier zones, Naias flexilis fruits in Zones V and VI and Erica Mackaii leaves in Zones VI and VII, suggests that both these elements are composed of genuinely native species. The presence of Erica Mackaii in an Interglacial deposit in the same area further suggests that survival through the last glaciation in or near Ireland itself is not impossible. Such new evidence in a controversy of long standing is very welcome, and it is to be hoped that further study, especially of the southern part of the island, will extend it. On the other hand, the recent conclusion of Sealy $(J$. Ecol., 37 (2), 365; December 1949) that Arbutus unedo cannot have survived glaciation in Ireland receives some support.

For Post-glacial time the most important generalization is that corresponding events appear to have occurred more or less synchronously with those of Denmark and western Europe in general. Differences of detail seem principally to have been caused by the more exposed and oceanic position of Ireland. This is expressed, for example, in the dominance of Empetrum heath rather than Calluna heath in Lateglacial and early Post-glacial time (Zones I-IV), and by a relatively late arrival of Pinus as a dominant. A similar picture is presented by the characteristic differences in the behaviour of oceanic species such as Hedera and Ilex, for several of which Ireland agrees more closely with Norway than with Denmark.

The maximum development of mixed oak woodland occurred in the climatic optimum of the Subboreal, and the subsequent general recession of woodland over the whole of Ireland, which entailed the complete elimination of the pine as a native tree, resulted from the climatic deterioration which prevented the regeneration of forests destroyed by man during the Sub-atlantic period. The first Mesolithic remains date from the Boreal and those of Eaxly Bronze Age from the Sub-boreal. 
A detailed chart correlates the events recorded for the various zones in Ireland with the stratigraphy worked out particularly by Godwin for England, Faegri for Norway, and Jessen for Denmark. This would have been more complete if the British data could have included reference to Pennington's work on the stratigraphy of the floor of Lake Windermere and Mitchell's pollen-analytical work with the South Berwickshire clays, which collectively provide some of the best evidence for Late-glacial chronology in Great Britain. This omission is, however, explained by the delay of two years during which this extremely important work was passing through the press.

H. G. BAKER

\section{GRAVITY AS A GEOLOGICAL FACTOR}

A GEOPHYSICAL Discussion on "Gravity as a Geological Factor" was held at the Royal Astronomical Society on March 3. The proceedings opened with a paper by Prof. O. T. Jones, who mentioned the various effects due to gravity, namely, landslips, creep and submarine slumping, all showing downhill movement of material. Among these effects are the structures proved in the Jurassic ironfield of Northamptonshire and the flap and cascade structures described from Iran. More doubtful in its application is the sliding under gravity in the Alps. Prof. H. Jeffreys suggested that the main effect of compression was to elevate the sedimentary rocks to such a height that the nappes became unstable and flowed downhill under gravity, thus producing the Alpine Nappes.

Prof. H. Jeffreys, in his contribution, said that after its early successes the idea of isostasy led to the supposition that at depths exceeding $50-100 \mathrm{~km}$. the material behaves like a viscous fluid for low stresses lasting a long time. The added weight produced by sedimentation is able to depress the crust, but as shown by Morley Davies and by E. M. Anderson, there is a limit to this effect, and something more is needed to produce the sinking than viscous outflow.

There are two types of distribution of viscosity at depth : in the first, the $20 \mathrm{~km}$. immediately under the surface has a finite strength of the order of laboratory strengths, and below this the material is viscous to great depths. In the second type of distribution the viscosity is confined to an intermediate layer. Both are contradicted by the observed distribution of gravity anomalies.

The sinking of the crust in regions of heavy sedimentation can no longer be regarded, Prof. Jeffreys said, as due to outflow produced by load. It needs spontaneous changes in a strong substratum, probably the same as those producing deep-focus earthquakes. Long fractures in a strong substratum and the infall of the outer parts could explain sinking geosynclines, ocean deeps, and rift valleys.

Dr. A. J. Bull described two types of structure which he considers have been produced by the move. ment of strata downhill under the force of gravity; namely, the Jura Mountains, which have moved bodily on the anhydrite beds, and a simple overfold, examples of which were shown from the London clay of Brockley and the Mesozoic cover of the Aar granite, Switzerland. $\mathrm{He}$ considers that gravity tends to equilibrium in the earth's crust, but this can be disturbed by radioactive heat and by changes in the specific gravity which the heat can induce.
Dr. J. G. Oldroyd referred to the rock markings mentioned by Prof. Jeffreys, and suggested that they might indicate the presence of regions in a moving rock where the yield-point is not exceeded. Slight inhomogeneity in the rock and boundary irregularities could cause the regions of actual plastic flow to occur in a complicated pattern, which might well be preserved as rock markings. Sudden fracture of a flowing rock can be accounted for by the hypothesis that a solid can rupture by flow or by fracture, with different stress criteria for the two types of failure. A gradual reduction of the hydrostatic pressure on a rock, while not interfering with the continuance of plastic flow, could make a brittle fracture increasingly probable.

Mr. N. L. Falcon showed illustrations of folding produced by gravity in the south-west of Persia. These structures were first described by Dr. J. V. Harrison and himself in the Geological Magazine of 1934. Particular interest is attached to the large size of the structures produced, although they are subsidiary to the main folding of the region. Their mode of origin appears to have been generally accepted by geologists throughout the world. Dr. Falcon referred to the negative gravity anomalies in the East African Rift Valley, which may be due to a considerable thickness of light sediments. Further examination is necessary in the way of bore holes and geophysical work before definite conclusions can be drawn.

Prof. S. E. Hollingworth discussed the strong disturbances produced by gravity in the Mesozoic of the Midlands, resulting in cambering and valley bulging. This has entailed a flowage in the rocks towards the valleys to a depth of at least $100 \mathrm{ft}$. below the surface. Tension in the interfluves and valley sides has produced step-and trough-faulting, while the clays at the foot of the valley slopes were crumpled, locally overturned and broken by reversed faults. $\mathrm{He}$ regards these structures as periglacial phenomena associated with deep perma-frost, in which the segregation of ground-water during freeze and thaw processes has played a vital part. The increased dip at the lower end of a downfaulted block is the result of sagging during tension.

Nature has in the Midlands made some moderatescale experiments, which may help to explain the larger tensional block-faulted structures in the Western United States and in regions of rifting, when the movement of the substratum is a matter of speculative inference.

Dr. R. I. B. Cooper commented on Prof. Jeffreys's suggestion that the major variations in the level of the earth's surface might be attributed to spontaneous changes in the substratum. He said that if they were due to density variations above a given level, then they would be equivalent to the Hayford conception of isostasy ; on the other hand, if the material circulated, then the principle would resemble that of Meinesz's convection currents. His own opinion is that the approximate constancy of mass per unit area over the earth's surface is a remarkable experimental fact ; for example, the mass deficiency of the oceans would be expected to give a gravity deficiency of $300 \mathrm{mgal}$, whereas, in fact, variations of only about \pm 20 mgal. are generally found.

Dr. Gilbert Wilson briefly summarized some cases in which sliding due to gravity has been invoked by French and Swiss geologists. Schardt was recognized as having first suggested that the nappes, after initial uplift, slid downwards under their own weight. The classic nappe theory, however, displaced this hypo- 